\section{PATERNIDADE EM FAMÍLIAS PÓS-DIVÓRCIO CUJO PAI DETÉM A GUARDA UNILATERAL DOS FILHOS}

\author{
Fatherhood in Post-Divorce Families whose Father has \\ Unilateral Custody Over the Children
}

\author{
Paternidad en Familias Pos Divorcio Cuyo Padre Detiene la \\ Guarda Unilateral de los Hijos
}

\section{Paternité au sein de Familles où le Père Divorcé a la Garde Unilatérale des Enfants}

\begin{abstract}
Resumo
Contemporaneamente, motivada por diversos movimentos sociais, a concepção de paternidade vem sofrendo mudanças, redefinindo-se diferentemente da paternidade tradicional, cujo pai detinha o poder e cumpria a responsabilidade pelo sustento familiar, dentre outras atribuições que o distanciavam da família. Hoje, alguns pais vivenciam modelos diferentes do tradicional, exercendo a paternidade com maior participação nas atividades domésticas, nos cuidados e na educação dos filhos e firmando vínculos próximos, afetuosos e amorosos com esses e a esposa. A partir desse novo cenário, delineado na literatura, o objetivo deste estudo é compreender o exercício da paternidade em famílias pós-divórcio cujo pai detém a guarda unilateral dos filhos. Participaram desta pesquisa de cunho qualitativo três pais com idade entre 29 e 44 anos, com a guarda unilateral, durante um período maior do que seis meses, com, pelo menos, um filho entre 6 e 13 anos de idade. Observou-se que os pais investigados exercem a paternidade de maneira diversa da tradicional, ainda que de forma diferenciada entre eles. Relacionam-se com os filhos afetuosamente e ressaltam o valor da proximidade e a satisfação que sentem por exercerem a paternidade dessa maneira. Por conviverem sozinhos com os filhos, acumulam as tarefas domésticas, os cuidados e a educação dos filhos e o lugar de provedor do lar. Em função disso, dividem com as crianças determinadas tarefas, geralmente as domésticas, enquanto, com relação aos custos com saúde, material escolar, vestimentas e eventuais necessidades de cuidados dos filhos, recebem ajuda de alguns componentes da família de origem. Para o sustento familiar, realizam atividades profissionais que possibilitam trabalho em casa e flexibilidade nos horários. Em dois dos casos, houve um distanciamento da mãe em relação à família do pai, porém em outro, a mãe recebia visitas regulares do filho.
\end{abstract}

Palavras-chave: paternidade; pai; guarda dos filhos; família; famílias pós-divórcio.
Artigo Original
Rogério Isotton ${ }^{(1)}$

Denise Falcke ${ }^{(2)}$

1) Mestre em Psicologia pela
UNISINOS.
2) Professora do Programa de Pós-
Graduação em Psicologia da UNISINOS. Abstract
The concept of fatherhood contemporaneously motivated by various social movements has
been changing, redefining itself differently from traditional fatherhood, whose father held
the power and fulfilled the responsibility for family maintenance, among other duties that
would distance him from the family. Today, some fathers experience different models from
the traditional one, exercising fatherhood with greater participation in domestic activities,
in the care and education of children, and establishing close warm and loving bonds to the
kids and wife. From this new scenario outlined in the literature, this study aims to understand
the fatherhood exercise in post-divorce families, whose father has unilateral custody over
the children. In this qualitative research, three fathers have participated, with ages between
29 and 44 years, with unilateral custody for a period longer than six months, and having at
least one child between 6 and 13 years of age. It was observed that the fathers investigated
exercised fatherhood in a diverse way from the traditional, albeit in a differentiated form
between them. They relate to the children affectionately, and emphasize the value of
closeness and the satisfaction they feel by exercising parenting this way. By living together

Recebido em: 02/06/2014 Revisado em: $28 / 04 / 2015$ Aceito em: 30/04/2015 
alone with the children, the parents build up the housework, the care and education of children, as well as a family provider role. As a result, they share certain tasks with the children, usually the housework, while the costs with health, school supplies, clothing and any possible care needs of children they receive assistance from some family members of origin. For their livelihood, the fathers carry out professional activities that enable them working at home, being able to manage it with flexible schedules. In two of the cases, there was a distancing from the mother towards the father's family, but in another, the mother received regular visits from the child.

Keywords: fatherhood; father; child custody; family; singleparent families.

\section{Resumen}

En estos tiempos y motivado por distintos movimientos sociales, la concepción de la paternidad sufre cambios, redefiniéndose de manera distinta de la paternidad tradicional cuyo padre detenía el poder y cumplía la responsabilidad del sustento familiar entre otras atribuciones que os alejaba de la familia. Hoy algunos padres vivencian modelos distintos del tradicional ejerciendo la paternidad con más participación de las actividades domésticas, de los cuidados y la educación de los hijos y sosteniendo vínculos próximos, afectuosos y amorosos con ellos y la esposa. A parte de este nuevo escenario delineado en la literatura, el objetivo de este estudio es comprender el ejercicio de la paternidad en familias pos divorcio cuyo padre detiene la guarda unilateral de los hijos. Tres padres participaron de esta investigación de carácter cualitativo con edad entre 29 y 44 años y la guarda unilateral a lo largo de un periodo mayor que 6 meses con por lo menos un hijo entre $6 y$ 13 años de edad. Se observó que los padres investigados ejercen la paternidad de manera distinta de la tradicional aunque sea de manera diferenciada entre ellos. Se relacionaron con los hijos con afecto y resaltan el valor de la proximidad y la satisfacción que sienten de ejercer la paternidad de esa manera. Por convivir solos con sus hijos, ellos acumulan las tareas domésticas, los cuidados y la educación de los hijos y el lugar de proveedor del hogar. A función de eso, dividen determinadas tareas con los niños, en general las domésticas, mientras que respecto a los costes de salud, de material escolar, de vestimenta y eventuales necesidades de cuidados de los hijos, ellos reciben ayuda de algunos miembros de la familia de origen. Para el sustento familiar ellos realizan actividades profesionales que os permitan trabajar en el hogar $y$ con flexibilidad de horarios. En dos de los casos, hubo un distanciamiento de la madre respecto la familia del padre, sin embargo en otro, la madre recibía visitas regulares del hijo.

Palabras clave: paternidad; padre; guarda de los hijos; familia; familias pos divorcio.

\section{Résumé}

Par suite de différents mouvements sociaux, la conception de paternité change et tend actuellement à se différencier de la conception traditionnelle, qui donnait au père le pouvoir et la responsabilité du soutien familial, en plus d'autres attributions qui l'éloignaient de la famille. Aujourd'hui, certains pères vivent

Revista Subjetividades, Fortaleza, 14(3): 486-498, dezembro., 2014 ces modèles différemment de ceux traditionnels; ils participent davantage aux activités ménagères, s'occupent des enfants et de leur éducation, en établissant des liens proches, affectueux et amoureux avec eux et avec leur épouse. Partant de ce nouveau scénario mis en avant dans la littérature, la présente étude vise à comprendre l'exercice de la paternité dans des familles où le père divorcé a la garde unilatérale des enfants. Trois pères âgés de 29 à 44 ans ont participé à cette recherche qualitative. Ils sont détenteurs de la garde unilatérale d'au moins un enfant de 6 à 13 ans pendant une période supérieure à six mois. Les résultats montrent que ces pères exercent, diversement, une paternité qui n'est pas basée sur le modèle traditionnel. Ils ont des relations affectueuses avec leurs enfants, insistent sur la valeur du rapprochement et sur la satisfaction de pouvoir exercer leur paternité de cette manière. Parce qu'ils vivent seuls avec leurs enfants, ils accumulent les tâches domestiques, les soins et l'éducation des enfants avec le rôle de soutien financier du foyer. $C$ 'est la raison pour laquelle ils divisent avec les enfants certaines activités, généralement ménagères, et sont aidés par des membres de la famille d'origine pour les frais de santé, de matériel scolaire, d'habillement et de soins éventuels. Pour le soutien de la famille, ils ont des activités professionnelles qui privilégient le travail à domicile et les horaires flexibles. Dans deux de ces cas, la mère s'est éloignée de la famille et du père; dans un autre, la mère recevait des visites régulières de son enfant.

Mots-clés: paternité; père; garde des enfants; famille; familles après divorce.

Considerando as mudanças que vêm ocorrendo na contemporaneidade, em relação ao exercício da paternidade, é possível localizar alguns movimentos entre os homens em direção a uma maior compreensão de seu papel de pai. Compreendendo seu papel, eles podem repensar sua postura diante da paternidade, o que inclui atitudes, emoções, busca de novos espaços, principalmente na família (Freitas, Coelho, \& Silva, 2007; Moreira \& Toneli, 2013). Dessa maneira, iniciou-se a reescrita do conceito de paternidade, que passa a incorporar novas características (Colman \& Colman, 1988; Moreira \& Toneli, 2013). Considera-se, portanto, importante rever o exercício da paternidade a partir desse novo olhar e verificar a aplicação deste novo modelo em famílias constituídas pelo pai e seus filhos. Outrossim, esta seara apresenta-se como um vasto campo de estudos, pois o número de publicações científicas nessa área ainda é escasso.

Por muito tempo, as mulheres predominaram na criação de suas crianças e são, em grande parte, as favoritas na opção pela guarda dos filhos (Dantas, 2003). Contudo, o homem vem assumindo um espaço, cada vez maior, de proximidade com os filhos (Silva, 2003), podendo elevar as possibilidades de ser o responsável pela criação desses (Moreira \& Toneli, 2013), mesmo sem a presença de 
uma companheira. Dessa forma, as famílias pós-divórcio chefiadas pelo pai, mesmo que ainda timidamente, vêm ganhando espaço e reconhecimento nas últimas décadas (Eggebeen, Snyder, \& Manning, 1996; Garasky \& Meyer, 1996; Souza, 2008).

Segundo o Código Civil, publicado em 2002, entre os deveres dos pais estão listados a educação, alimentação, provimento financeiro e a guarda dos filhos. Pelo artigo 1632, a separação judicial ou divórcio não altera a relação entre pais e filhos, e a guarda das crianças deve ficar com o cônjuge que tiver melhores condições de criá-los, independente de gênero. Embora as leis prevejam igualdade entre pai e mãe quanto à possibilidade da guarda dos filhos após o divórcio, os dados mostram uma tendência cultural de que a mãe fique com a guarda (Dantas, 2003). Em 1998, segundo o Instituto Brasileiro Geográfico e Estatística (IBGE), dos divórcios concedidos em primeira instância a casais com filhos menores de idade, em $90,77 \%$ dos casos a guarda dos filhos ficou com a mãe, enquanto somente 5,64\% dos filhos ficaram com os pais. Esse mesmo dado, em 2008, manteve-se estável, somando $88,77 \%$ para as mães e $5,5 \%$ para os pais.

O movimento das mulheres em busca de reconhecimento social ocasionou a necessidade de uma reelaboração de significantes do estereótipo masculino e feminino (Kehl, 1996). O lugar social conquistado pela mulher contemporânea abriu espaço para o homem também recolocar-se socialmente (Eggebeen, 2002; Garbar \& Theodore, 2000), aumentando sua participação nas tarefas domésticas, educação e criação dos filhos (Gabriel \& Dias, 2011; Hennigen, 2010; Magalhães, 2007), envolvimento antes rechaçado no meio masculino por ser predominantemente feminino (Staudt \& Wagner, 2008). A partir dos desdobramentos histórico-sociais da dialética entre os gêneros feminino e masculino, pode emergir um homem que não negue totalmente características como rigidez e supremacia, mas que consiga compor com a sensibilidade, amorosidade e afetuosidade (Badinter, 1993).

Essa nova configuração do masculino abre caminho para uma reconfiguração da paternidade (Hennigen, 2010), outrora caracterizada pela suprema autoridade, distanciamento e provimento financeiro da família (Badinter, 1993; Garbar \& Theodore, 2000). O pai deixa de acumular todo o poder sobre sua família para dividir a autoridade parental com a mãe, em tom de igualdade. Além disso, o pai começa a participar dos cuidados com o filho: higiene, alimentação, diversão e lazer (Hennigen, 2010; Piccinini, Silva, Gonçalves, Lopes, \& Tudge, 2012). Assim, a afirmação de Colman e Colman (1988) de que os estilos de exercer a paternidade tomam novos rumos parece estar se concretizando.

Staudt (2007) afirma que ainda está presente, no exercício da paternidade, a detenção da autoridade, a responsabilidade pela preservação da segurança e do sustento da família. Porém, acrescenta que os pais revelamse mais afetivos e próximos dos filhos. Freitas, Coelho, e Silva (2007), ao final de um estudo sobre os sentimentos de paternidade durante a gestação e após o nascimento do bebê, afirmam que os pais reúnem características do modelo tradicional e outras que o situam no novo estilo de paternidade. Ao estreitar os laços com a mãe e o bebê, participando da gestação, o pai tenderá a ter um vínculo mais próximo com seu filho. Segundo os autores, participar da gestação do filho faz emergir sentimentos de proximidade e envolvimento, o que pode, também, minimizar os conflitos com a esposa.

Um pai pode exercer sua função a partir do modelo de paternidade que teve quando criança (Gabriel \& Dias, 2011; Yablonsky, 1990). É provável que o pai de hoje tenha sido criado nos moldes tradicionais de paternidade e não tenha recebido o preparo para se tornar um pai próximo à família, ao lar e aos filhos (Colman \& Colman, 1988). O modelo pode ser seguido e reproduzido, quando vivenciou uma experiência positiva. Quando as experiências foram negativas, o pai que se conscientizar de que pode prejudicar seu filho (Yablonsky, 1990), ou que simplesmente queira exercer uma paternidade diferente da tradicional (Colman \& Colman, 1988), pode rever o modelo paterno que teve e buscar novos exemplos, exercendo a sua função de maneira a contemplar os quesitos do modelo contemporâneo de paternidade (Colman \& Colman, 1988; Gabriel \& Dias, 2011; Yablonsky, 1990). O exercício da função paterna, distante de ser desempenhada de forma isolada, sofre influência da configuração familiar, da esposa, dos irmãos, bem como dos momentos do ciclo vital que o pai está vivendo, e do estado emocional e social do homem. Além disso, a paternidade também pode ser influenciada pelo próprio filho, considerando seu desenvolvimento vital e suas características (Yablonsky, 1990).

A partir de tais movimentos, seria possível pensar que existem pais que podem cuidar dos filhos tão bem quanto a mãe? Nos casos de separação, em que o pai deseja a proximidade e a companhia dos filhos poderia receber um tratamento de igualdade no páreo pela guarda dos filhos? Autores afirmam que a maternidade ainda é modelo na criação e educação dos filhos e nos cuidados com o lar (Bandeira \& Seidl-de-Moura, 2012; Hennigen, 2010). É a este modelo que a paternidade se compara e, por vezes, se opõe. Entretanto, as mudanças contemporâneas nas funções paterna e materna mobilizam o pai a exercer as funções de cuidado, educação dos filhos, realização das atividades domésticas, aproximando-se cada vez mais de seus filhos (Souza, 2008).

Garbare Theodore(2000) afirmam que o pai que fica com 
a tutela dos filhos, após a separação, enfrenta dificuldades relacionadas às atividades domésticas, provavelmente em função do despreparo. Pode ocorrer também que o pai decida por empregos ou atividades remuneradas que propiciem a proximidade do lar e dos filhos, bem como de maior disponibilidade de tempo livre, podendo enfrentar, inclusive, uma diminuição da renda financeira por conta dessa decisão. O acúmulo de tarefas, que pode sobrecarregar o pai, somando-se às questões emocionais, como ausência do outro cônjuge e solidão, faz com que alguns tendam ao desânimo. Já outros percebem que a falta do outro cônjuge possibilita a experiência de papéis e funções antes não exercidas que levam ao orgulho de exercitar a paternidade de maneira mais próxima dos filhos (Garbar \& Theodore, 2000). Pode ocorrer que o pai, quando a mãe se distancia, faça movimentos compensatórios na tentativa de suprir a ausência dela (Yablonsky, 1990).

Um estudo realizado por Dantas (2003), com oito famílias de classe socioeconômica média e alta do Rio de Janeiro, mostrou que os pais, após a separação do casal, mesmo os que não ficaram com a guarda de seus filhos, desejam manter um vínculo próximo com eles. Ao falarem de seus filhos, os pais demonstraram amor por eles e interesse em participar da vida daqueles.

Buscando comparar famílias pós-divórcio femininas e masculinas, Jiménez (2003) estudou a relação pai-filho em 108 famílias chefiadas por um dos genitores, 93 maternas e 15 paternas, no México. O pesquisador destacou as seguintes diferenças: as chefiadas pelo pai somam um número consideravelmente menor e dedicam menos atenção aos cuidados de saúde, à alimentação, ao dormir e brincar, com uma participação maior da avó nessas atividades. Ressaltase como semelhança entre os dois arranjos familiares a participação na vida escolar do filho.

Outros estudos internacionais realizados, comparando diferentes configurações de família, revelaram que pais chefes de famílias pós-divórcio: a) dispensam mais tempo com os cuidados dos filhos do que os pais em famílias intactas, e menos do que as mães em famílias pós-divórcio e intactas (Hook \& Chalasani, 2008); b) dedicam mais tempo brincando com seus filhos do que as mães e pais casados (Hook \& Chalasani, 2008); c) dedicam mais tempo às atividades da casa e menos tempo em atividades sociais do que os pais casados (Hook \& Chalasani, 2008); d) em alimentação em casa, utilidades, roupas e em educação dos filhos, os gastos são menores se comparado às famílias chefiadas pela mãe e intactas (Ziol-Guest, 2009); e) os pais trabalham menos em tempo integral fora de casa $(76 \%) \mathrm{e}$ as mães trabalham mais (56\%) do que em famílias intactas (90\% e 43\%, respectivamente) (Hook \& Chalasani, 2008); f) há um maior consumo de álcool e tabaco nas famílias chefiadas pelo pai, ultrapassando as chefiadas pela mãe e as intactas (Ziol-Guest, 2009); g) crianças em famílias chefiadas por homens estão mais vulneráveis, se comparado com as famílias intactas e, tratando-se de condições socioeconômicas, as famílias chefiadas por mulheres estão em maior desvantagem, seguidas das chefiadas por homens e depois das intactas (Leininger \& Ziol-Guest, 2008).

Observa-se que a maioria dos estudos analisados são levantamentos quantitativos que buscam a diferenciação do exercício da paternidade em famílias chefiadas por um dos genitores, em comparação com outros arranjos familiares. Como se trata de uma temática de interesse que vem sendo ampliada na contemporaneidade, merece atenção e dedicação, em especial, mediante a realização de estudos qualitativos que se dediquem ao aprofundamento da compreensão sobre o exercício da paternidade. Dessa maneira, o objetivo deste estudo é compreender como os pais que detêm a guarda unilateral de seus filhos em famílias pós-divórcio percebem sua experiência como pai e o exercício da paternidade. Salienta-se, ainda, que este artigo é um recorte dos dados coletados para a dissertação de mestrado do primeiro autor deste texto.

\section{Método}

Para este estudo, seguiram-se os procedimentos qualitativos. Segundo Creswell (2007), na pesquisa qualitativa, os pesquisadores envolvem os participantes com o objetivo de investigar os fenômenos de maneira aprofundada. Além disso, a pesquisa qualitativa é voltada para a investigação de casos empíricos, quando busca, em detalhes, as características do dia a dia, sem desconsiderar aspectos culturais que envolvem o fenômeno.

\section{Participantes}

Os participantes foram selecionados, por conveniência e pela indicação de conhecidos, três pais (P1, P2 e P3) que já vivenciaram um processo de separação, que possuem a guarda unilateral, ainda que provisória, por mais de seis meses, de, pelo menos, um filho biológico com idade entre 6 e 13 anos, e que não mantém um vínculo em coabitação com outra esposa.

O participante $\mathrm{P} 1$ conviveu pouco com seu pai biológico e afirmou não ter boas lembranças desta relação. Já com seu padrasto, conviveu mais tempo e descreveu lembranças positivas da experiência com ele. P2 e P3 viveram com os pais biológicos, porém com experiências opostas. P2 relatou que teve uma ótima relação com seu pai enquanto P3 afirmou que seu pai foi presente fisicamente e ausente afetivamente. A Tabela 1 apresenta uma complementação da caracterização dos participantes da pesquisa. 
Tabela 1

Dados sóciodemográficos dos participantes

\begin{tabular}{cccccccc}
\hline Pai & Idade & Escolaridade & Profissão & $\begin{array}{c}\text { Núm. de } \\
\text { filhos }\end{array}$ & $\begin{array}{c}\text { Filho entre } \\
\text { 6 e 13 anos }\end{array}$ & $\begin{array}{c}\text { Tipo da } \\
\text { guarda }\end{array}$ & $\begin{array}{c}\text { Tempo de } \\
\text { guarda }\end{array}$ \\
\hline P1 & 44 & $\begin{array}{c}\text { Ensino Médio } \\
\text { Completo }\end{array}$ & $\begin{array}{c}\text { Auxiliar de } \\
\text { Arrecadação }\end{array}$ & 1 & 6 anos & Unilateral & 6 meses \\
P2 & 29 & $\begin{array}{c}\text { Ensino Médio } \\
\text { Completo }\end{array}$ & $\begin{array}{c}\text { Profissional } \\
\text { Liberal }\end{array}$ & 1 & 13 anos & $\begin{array}{c}\text { Unilateral } \\
\text { (Provisória) }\end{array}$ & $\begin{array}{c}1 \text { ano e } 7 \\
\text { meses }\end{array}$ \\
P3 & 43 & $\begin{array}{c}\text { Ensino Superior } \\
\text { Incompleto }\end{array}$ & $\begin{array}{c}\text { Profissional } \\
\text { Liberal }\end{array}$ & 3 & $\begin{array}{c}\text { Um filho } \\
\text { com 10 } \\
\text { anos. }\end{array}$ & Unilateral & 5 anos \\
\hline
\end{tabular}

\section{Instrumentos}

Os instrumentos empregados para a execução da pesquisa foram basicamente: Ficha de Dados Sociodemográficos, com o objetivo de identificar e registrar os dados sociodemográficos dos pais; e entrevistas semiestruturadas, que objetivaram levantar dados sobre a paternidade em famílias pós-divórcio chefiadas pelo pai. Os assuntos focalizados nestas entrevistas foram o relacionamento com o pai na família de origem, quando criança e adolescente; as características do exercício da paternidade antes e após a separação e guarda dos filhos, bem como da rotina familiar após a separação e guarda dos filhos; a participação da mãe na família dos entrevistados e a atuação de outros familiares nas atividades domésticas e de criação dos filhos.

\section{Procedimentos}

Após a seleção dos participantes, realizou-se o primeiro contato, pelo telefone, cujo objetivo foi explicar as características, os objetivos e o envolvimento dos participantes. Com os que consentiram verbalmente, foi agendada a primeira entrevista na residência dos participantes, com a presença exclusiva do pai. Com maior detalhamento, explicaram-se as características, os objetivos, o procedimento e o envolvimento dos participantes. Realizou-se, conjuntamente, a leitura do Termo de Consentimento Livre e Esclarecido (TCLE), o qual foi assinado em duas vias, uma para o pesquisador e outra para o participante. Houve um momento, também, para esclarecimento de possíveis dúvidas. Foi realizado o preenchimento da Ficha de Dados Sociodemográficos após o consentimento dos participantes. As entrevistas foram realizadas individualmente com os pais, havendo alguns casos em que foi necessário mais um encontro para cumprir todos os quesitos previstos nesse diálogo. Os encontros foram registrados em áudio e, após, foram transcritos. Para que fosse executada a pesquisa e garantir os quesitos éticos, o projeto foi submetido ao Comitê de Ética em Pesquisa da Universidade do Vale do Rio dos Sinos e aprovado sob o parecer número 10/030.

\section{Análise dos Dados}

Com o corpus de dados estruturado, passou-se à análise dos resultados, cuja metodologia está fundamentada na técnica de análise de conteúdo (Bardin, 2009). Com base na diferenciação e no agrupamento do conteúdo coletado, bem como no critério de categorização semântica, cuja classificação é regida pelos significados, pelos temas desenvolvidos e explícitos no corpus de dados, realizou-se a categorização (Bardin, 2009). Foram três as categorias criadas: modelos de paternidade, significado da paternidade e paternidade em família pós-divórcio chefiada pelo pai. Esta última foi dividida em quatro subcategorias: aspectos da relação entre pai e filho, atividades domésticas, aspectos financeiros e participação da mãe e da família extensa. Todas as categorias são apresentadas e discutidas na seção a seguir.

\section{Resultados e Discussão}

Apresenta-se a definição de cada categoria, bem como alguns recortes que fundamentam a criação desta. Juntamente, realiza-se o diálogo entre as concepções de autores, ligadas ao tema, e o material empírico coletado.

\section{Modelos de Paternidade}

A categoria modelos de paternidade reúne o conteúdo relacionado à descrição que os participantes fizeram de seus pais ou a outros modelos de paternidade. Foram relacionados os sentimentos expressos no discurso a respeito da relação que os participantes tiveram do papel do pai na família, entre outros aspectos que contribuem para a construção do modelo de paternidade que os participantes internalizaram. 
Foram observadas características tradicionais nos modelos de paternidade que os participantes vivenciaram durante a infância e adolescência. Aponta-se, para exemplificar, a seguinte descrição: "Ele me dava tudo o que eu queria, mas não me dava o fundamental que era a presença dele" (P3). Nessa fala, fica evidente o cumprimento do sustento financeiro da família como inerente ao papel do pai. A proximidade, contudo, foi descrita como um atributo preferencialmente da mãe, sendo o distanciamento e a disciplina severa relacionados à figura paterna, como se pode verificar nos seguintes exemplos: "Eu tinha mais facilidade com a minha mãe de pedir o carro. Se tivesse que pedir para sair era tudo com a minha mãe. O pai supervisionava de longe, quando precisava de uma coisa mais grave ele entrava, com mais energia" (P3). Observou-se, também, o relato de um modelo de pai ausente, que, após o divórcio, não participou da vida do filho: "Com o meu pai, eu nunca tive um bom relacionamento, porque ele abandonou eu e minha mãe. Foi me procurar quando eu tinha sete anos" (P1). O modelo tradicional de paternidade estava associado ao distanciamento afetivo, o que, por si só, já favorecia o abandono paterno após o divórcio.

Por outro lado, verificaram-se traços não tradicionais no modelo de pai que os participantes tiverem. Destacamse os seguintes recortes: "Meu pai sempre disse que não era para mim ter medo do novo. O meu pai sempre me ensinou a escutar o coração" (P2); "Eu tenho um bom relacionamento com quem eu chamo de pai, meu padrasto. Eu fui criado assim, minha mãe e meu padrasto, sempre conversando" (P1). Percebe-se, por meio dessas falas, um modelo de educação concretizado pelo diálogo e pela compreensão, revelando proximidade entre pai e filho (Gabriel \& Dias, 2011).

Exercendo a interdição e favorecendo a autonomia, observa-se um pai que estabelece limites, como na seguinte situação relatada:

Deixa o guri aí, tem que aprender a ser homem, ele quer ficar em casa, deixa ele ficar em casa. $\mathrm{Na}$ adolescência, ele me dava a chave do carro dele para sair. Meu padrasto dizia isso: Olha, se tu não quer trabalhar na oficina, não trabalha, vai trabalha em 500 empregos, uma hora tu vai achar, mas tem que trabalhar. (P1)

Emerge do discurso dos participantes, indicativos de paternidade participativa das atividades domésticas e das atividades escolares dos filhos, bem como dos momentos de lazer:

Era sempre ele que organizava as coisas da casa. Era o meu pai que levava a gente nas lojas para escolher roupa, corrigir os temas, que passava as informações de horários que a gente ia ficar na rua, com quem que a gente podia brincar. (P2)

Destaca-se, subsequentemente, a preocupação de transmitir aos filhos a possibilidade de divisão das tarefas domésticas: "Ele que botava a gente para lavar louça. Ele dizia que o homem tinha que aprender a lavar louça para nunca se casar com uma mulher só porque ela lavava louça e cozinhava" (P2). É possível pensarmos que a função paterna neste contexto unia autoridade, disciplina, proximidade, amor e afeto, como reflexo de uma possível transição entre o modelo tradicional de paternidade e o que tem se observado atualmente. Por vezes, na fala dos participantes, é possível perceber que o pai parecia confundir-se entre disciplina e afeto, arrependendo-se de exercer a severidade e buscando compensar com amor e afetividade: "Às vezes ele batia na gente, e de noite, sempre antes de dormir, ele ia lá no quarto pedir desculpas" (P2).

Autores afirmam que os pais exercem sua paternidade resgatando aspectos do estilo de paternidade que, quando crianças, vivenciaram com seus próprios pais. Caso a experiência tenha sido negativa, os pais podem reavaliar o modelo vivenciado, para buscar novas imagens que fundamentem a paternidade atual, substituindo o que entendem ser negativo, pelo que acreditam ser positivo (Colman \& Colman, 1988; Gabriel \& Dias, 2011; Yablonsky, 1990).

Nesse sentido, é possível perceber a relação, elaborada pelos participantes, entre o exercício atual da paternidade e o estilo de paternidade que vivenciaram quando crianças. Quando o pai guarda boas lembranças da convivência com seu próprio pai, possivelmente reproduz o modelo de pai que experienciou. Observa-se que P1 e P2 encontram características do modelo de paternidade de seus pais que podem reproduzir com seus filhos. P2 encontrava todas as respostas que precisasse ao procurar o seu próprio pai e, atualmente, evita deixar seu filho sem respostas. Aprendeu, com seu pai, a seguir o caminho que lhe mostra o coração e busca ensinar seu filho a seguir seus próprios sentimentos e princípios. Considera seu pai um super-herói e tenta ser um super-herói para seu filho. P2 parece acumular tudo o que ele precisava da função paterna: "Meu pai foi o meu herói, era meu melhor amigo. Eu queria me vestir como ele, queria fazer a barba como ele, eu queria saber o que ele sabia. Meu pai foi um técnico de futebol" (P2).

Nessa mesma direção, $\mathrm{P} 1$, que considera o padrasto como pai, já que o pai biológico foi ausente tanto afetuosa quanto fisicamente, objetiva exercer a paternidade com base no modelo que experienciou com o padrasto e parece ter consciência de que a ausência desta figura masculina não faria bem para seu filho. P1 construiu dois modelos de paternidade, um a partir de seu pai e outro a partir de seu 
padrasto. Dessa forma, o discurso de P1 revela que oferece ao seu filho proteção, amor, afeto, lazer e acompanhamento nas atividades escolares. No entanto, talvez como uma tentativa de não repetir o modelo de paternidade de seu pai, P1 invista excessivamente na proximidade com o filho, não distante, em alguns momentos, da superproteção. Tomando como modelo o abandono do pai biológico, parece desempenhar o extremo oposto, também não adequado ao desenvolvimento saudável do filho. Nesse sentido, P2 que teve duas figuras parentais (o pai biológico e o padrasto) parece reconhecer o padrasto como modelo a ser seguido, mas, em certa medida, percebe-se que o modelo do pai biológico ainda marca a sua vida e pode estar contribuindo para que ele tenha dificuldade em exercer a função paterna, sem ter a sensação de que está prejudicando o filho.

Em oposição a P1 e P2, o participante que não teve "o pai que sonhou" (P3) parece não desejar seguir o modelo de paternidade que vivenciou. Considera que seu pai exerceu a paternidade com pouca afetuosidade, o que denota ter marcado sua história. Embora afirme que o pai atendia suas necessidades materiais, considera não ter sido suficiente. Atualmente, indica atribuir importância elevada à afetuosidade, à amorosidade e à proximidade com os filhos, possivelmente para evitar que eles sintam a mesma dor que sentia. Contrapondo seu pai que não participava de suas atividades, $\mathrm{P} 3$ não deixa de presenciar os jogos de futebol, as atividades do colégio e se preocupa em propiciar momentos de lazer aos filhos. Explicita a possibilidade de ter vivenciado um modelo de paternidade carregado de características que não deseja oferecer aos seus filhos, pois, possivelmente, percebe que pode prejudicar o desenvolvimento deles. Por consequência, elaborou um modelo de paternidade composto por características adversas às de seu pai, provavelmente baseado em imagens de outros pais que, talvez, sonhasse ter, na busca de cumprir seu desejo de ser para seus filhos o pai que sonhou ter quando criança, mas que não teve.

Observa-se que dois participantes seguem o modelo de paternidade que tiveram, enquanto um deles compunha seu estilo de paternidade excluindo características que não considerava positiva em seu pai. Buscaram em seus pais possíveis referências, entre as quais podem ser incluídas determinadas características, se interpretadas como positivas, ou descartadas, caso reflitam negativamente no conceito de paternidade que formaram para si e para os filhos: "Meu padrasto, não batia, então eu não bato" (P1). "No momento que o Cleomar nasceu, eu sempre tentei ser um espelho do relacionamento que foi comigo e com o meu pai. [...] Passar um pouco para ele. Coisa que eu aprendi com o meu pai" (P2). "Meu pai nunca foi num jogo meu, eu nunca deixei de ver uma medalha que os meus filhos têm" (P3).

\section{Significado de Paternidade}

A partir do conteúdo relatado pelos participantes, foi possível identificar o significado de paternidade que elaboraram. Evidenciou-se nos relatos que ser pai é participar da vida do filho desde a gestação, incluindo continência à esposa e participação nos cuidados básicos com o bebê. "Desde o começo, sempre fui em todas as consultas dela, pré-natal, tudo, acompanhei ela em tudo" (P1). Verificou-se que é fundamental à paternidade estar próximo aos filhos, ter uma atitude afetiva. É ser companheiro, é saber ouvir, ensinar, é não deixar o filho sem respostas, buscando compreendê-lo e não recriminálo. "Acho que ser companheiro e presente" (P3). "Ser pai também é ter amor pelo filho, carinho" (P1). "Eu dou total liberdade de ele perguntar o que ele quiser. Eu nunca posso deixar ele sem resposta, eu deixo ele questionar bastante, se não estiver errado, eu vou entender, e se tiver errado, vai ter que entender" (P2). Destaca-se também no significado da paternidade a importância de acompanhar as atividades da criança, participar ativamente da educação e dos cuidados com a saúde daqueles, dentre outros aspectos presentes numa convivência que aproxima afetuosamente pai e filho. "Eu vou nas reuniões de escola, vou no dia das mães, vou no dia dos pais, levo eles sempre nos amigos, eu vou em todos os jogos deles" (P3). "Estava doente, quem corria com ele era eu" (P1). Verificou-se ainda, que o exercício das atividades domésticas e do sustento do lar integra o significado de paternidade. Por vezes, considerando o fato de serem pais separados e com a guarda dos filhos, observou-se que a paternidade assume um caráter de excessiva proteção e a flexibilização da função que interdita e estabelece limites.

Ao analisar o que os pais entendem por paternidade, é possível verificar que a afetividade, a proximidade, a participação direta na educação dos filhos e nas atividades domésticas integram o exercício da paternidade (Gabriel \& Dias, 2011), que já carrega historicamente a responsabilidade pelo sustento da família. Distantes da paternidade tradicional, cujas características são o distanciamento dos filhos, da família, do lar, a responsabilidade pelo provimento financeiro e a detenção da autoridade (Grzybowski, 2007), esses pais mostram fazer valer o novo modelo de pai que se propõe na contemporaneidade, ou seja, uma paternidade ligada ao afeto, à proximidade, à responsabilidade de educar, de alimentar e de cuidar da prole (Silva, 2003).

Por estar próximo dos filhos, acompanhá-los em suas atividades e criar os filhos sozinho, P3 considera-se um exemplo para a paternidade contemporânea. Outro participante, nessa mesma direção, demonstrou satisfação em poder desempenhar a paternidade, principalmente após a obtenção da guarda. Contudo, observaram-se dois momentos no exercício da paternidade, um antes da separação e outro após a separação e obtenção da guarda 
unilateral. Verificou-se uma mudança considerável na maneira de exercer a paternidade após a separação. P3 ficou com a guarda logo após a separação, relatou ter mudado o conceito de paternidade, evidenciando uma participação mais intensa na vida dos filhos após a separação. P1 e P2, que buscaram a troca da guarda, experimentaram dois momentos da paternidade, além da fase em que ainda era casado: um, logo após a separação, quando ocorreu o afastamento dos filhos, em vista de não possuírem a guarda unilateral, e outro, vivido com a troca de guarda, na volta à convivência intensa com o filho, sem a presença da mãe no núcleo familiar, vivendo a responsabilidade da dupla jornada, isto é, assumindo cuidados com o filho e com o lar e o sustento financeiro de ambos. Observa-se que após a posse da guarda unilateral, os pais modificaram sua maneira de viver e compreender a paternidade.

O conceito de paternidade, cujas características incluem as responsabilidades ligadas ao filho e ligadas ao lar, faz emergir a ideia de um pai herói, conforme atestam as palavras de um dos participantes: "Eu botava na cabeça que aquela criança só contava comigo. Isso me ajudava, porque daí eu me sentia um pouquinho herói e isso me estimulava a trabalhar, levantar cedo" (P2). P1 buscou juridicamente a guarda do filho para protegê-lo dos maus-tratos advindos da convivência com a mãe (P1). P2 recebeu seu filho que deixou a casa da mãe pelo mesmo motivo. O que se observa a partir dos respectivos recortes: "No dia 30, sete e meia da noite, quando ele me entregou [documentação da guarda provisória] não pensei duas vezes, fui buscar ele [o filho]" (P1). "Daí ele [o filho]: Pai! Eu não quero mais voltar para casa, quero ficar aqui" (P2).

Os pais entrevistados dizem se sentir responsáveis por acompanhar tudo que acontece com os filhos e com o lar, auxiliando, educando, orientando, provendo, se percebendo, por isso, como pais heróis, exemplos para os demais. Formulações que se evidenciam a partir dos seguintes recortes: "Cara, se tiver um exemplo de pai até agora sou eu. Porque eu levo meus filhos no futebol, eu levo os meus filhos onde eu vou, tô sempre com eles" (P3).

Para esses pais, a paternidade envolve o acompanhamento efetivo do filho. A relação entre pai e filho é intermediada pelo diálogo, através do qual buscam educar o filho. Demonstram exercer sua paternidade fundamentada na confiança e cumplicidade. No caso do participante cujo filho está ingressando na adolescência, sua função é zelar pelo filho, visando protegê-lo e prepará-lo para os relacionamentos sociais.

Outro aspecto que os pais incluem em seu conceito de paternidade é o desempenho das atividades domésticas e a responsabilidade pelo sustento do lar. Pelo relato dos três pais, essas responsabilidades são desempenhadas de maneira parecida. Dois dos três casos pesquisados demonstraram que as atividades domésticas, exceto a alimentação, não são realizadas com rigor, mas com certa flexibilidade. $\mathrm{Na}$ limpeza da casa, por exemplo, organizam-se semanalmente e contam com o auxílio dos filhos. No entanto, o terceiro pai afirma exercer tais atividades com maior severidade e não conta com a participação do filho.

Além disso, a característica que emergiu como parte mais relevante do significado de paternidade foi o companheirismo. Ser pai, para os participantes deste estudo, é compreender o filho muito mais do que punir, é ser o amigo a quem o filho poderá recorrer para o esclarecimento de dúvidas relacionadas à fase vital na qual se encontram, é buscar exemplos para resolver seus problemas, para aconselhar-se e pedir opinião.

\section{Paternidade em Famílias Pós-divórcio Chefiadas pelo Pai}

Nesta categoria, foram agrupados os principais aspectos do exercício da paternidade em famílias cujo pai detém a guarda unilateral dos filhos. Os aspectos considerados foram: a relação entre pai e filho, atividades domésticas, aspectos financeiros e participação da mãe da família extensa.

No que tange à relação entre pai e filho, o aspecto da afetividade pode ser destacada: "Estou sempre dando beijo e abraço nele" (P1). "É a relação de amigo" (P3). Percebese que os pais demonstram afetividade e são compreensíveis na relação com os filhos. Dois participantes afirmam que os filhos são companheiros e parecem dar liberdade a eles no que se refere a determinados assuntos como se fossem amigos. Contudo, cabe questionar o limite dessa relação. Certamente, uma maior proximidade entre pai e filho é importante para o desenvolvimento saudável da criança (Souza \& Benetti, 2009), porém, quando esse vínculo é demasiadamente estreito, pode tornar difusas as fronteiras, o que implica tornar indefinidos ou confusos os papéis que cada um exerce na família, ou interferir na organização dos subsistemas familiares e na hierarquia entre pai e filho. Verifica-se que dois participantes dormem com seus filhos, como se os filhos passassem a ocupar o lugar do cônjuge ausente, preenchendo o vazio deixado por este. "A gente vai para o mesmo quarto. Eles têm o quarto deles, mas eles só dormem no quarto deles quando a gente briga” (P3).

Garbar e Theodore (2000) afirmam que a criança pode ocupar o espaço que a mãe ocupava, e o pai pode compartilhar seus sentimentos paternos e marital. Pode ocorrer, ainda, de o filho venha ocupar o papel de cuidador, ou o pai tentar compensar a ausência da mãe para os filhos. De todas as formas, verifica-se um desequilíbrio no exercício dos papéis que cabem ao pai e ao filho, impactando na dinâmica de 
funcionamento da família. O que parece ocorrer, nos casos dos dois participantes, é, efetivamente, uma tentativa de compensar a ausência da mãe. Um deles afirmou ser uma mãe para seus filhos, enquanto o outro faz tudo para o filho, como se tivesse que ser a mãe dele.

Quanto à preservação da saúde dos filhos, dois participantes afirmaram que os filhos apresentaram melhoras após a troca da guarda. Além disso, quando os filhos se machucam acidentalmente ou adoecem, tomam os devidos cuidados, levando ao médico, quando necessário: "Desde que ele veio para cá, mais que uma gripezinha, não deu. Eu cuido" (P1). "Cleomar usava o nebulizador a cada dois dias. Em pouco tempo que ele está aqui, já descartou o nebulizador. Fiz um remedinho para ele, caseiro. Ele tem asma" (P2).

A respeito dos cuidados com a alimentação, dois pais cuidam da alimentação ao mesmo tempo em que dividem essa responsabilidade com os filhos, enquanto o outro, possivelmente em função da idade da criança, procura deixar a alimentação ao alcance dele, antecipadamente preparada: "Às vezes pego e digo: 'Cleomar, não pode ter ovo frito no dia tal porque a gente já comeu bife frito ontem"” (P2). "Tento acordar um pouquinho mais cedo para fazer umas torradas para eles, quando eu não faço, eles fazem" (P3).

Segundo Bandeira e Seidl-de-Moura (2012), a mãe é uma referência na criação dos filhos e nas tarefas domésticas, com a qual os pais podem comparar-se ou opor-se. Dois participantes mostraram uma tendência à comparação, ao revelarem certo exercício da maternidade no desempenho da sua função paterna. Um deles, em contrapartida, critica a postura materna que torna os filhos frágeis e dependentes, dizendo que as mães estragam os filhos. No entanto, ele próprio mantém práticas que o aproximam da função materna, o que, num contexto de família constituída pelo pai e seus filhos, pode ser uma necessidade. O pai precisa dar conta de atividades desempenhadas tradicionalmente pela mulher, rompendo o estereótipo tradicional de masculinidade (Kehl, 1996) e paternidade (Badinter, 1993; Colman \& Colman, 1988; Garbar \& Theodore, 2000).

No quesito educação dos filhos, observou-se a importância que parece ser atribuída ao diálogo e à compreensão dos filhos, por vezes incentivando a autonomia destes: "Desde pequeno eles são assim, pode fazer sujeira ao redor do prato, sujar o chão: "Te vira"”. (P3). "Eu converso muito com o Cleomar e ajudo ele a entender" (P2). É possível evidenciar que os pais, principalmente dois deles, propiciam um incentivo e uma educação com vistas à autonomia, acreditando ser importante que as crianças aprendam a ser responsáveis pelos seus atos. Mostram ao filho que uma atitude impensada gera consequências, as quais precisam ser assumidas. É dessa maneira que ambos os pais apontam para uma paternidade dosada de limites e proteção. Ao contrário, o terceiro participante, possivelmente para compensar a negligência que o filho afirma ter recebido da mãe e também como possível forma de não se aproximar da imagem do seu pai biológico, que o abandonou, demonstra proteger o filho exageradamente. Demonstra que a paternidade está muito mais ligada à proteção do que ao estabelecimento de limites que visam equilibrar ambas as dimensões.

Evidenciou-se que os pais dedicam momentos de lazer com os filhos: "Vamos numa pracinha, vamos ver o trem, vou no shopping com ele" (P1). "A gente joga videogame juntos, a gente pára para ver futebol juntos" (P2). Também demonstraram participar das atividades escolares: "Eu vou nas reuniões de escola, vou no dia das mães, vou no dia dos pais. Eu e ele passamos dois dias, num final de semana, fazendo uma maquete para o colégio" (P3).

Os pais relataram que realizam as atividades domésticas de maneira flexível e que as dividem com os filhos, no caso de dois dos participantes. "Em casa não é aquele primor, limpinha, tudo direitinho. Mas daí, chegou a hora de limpeza, daí a gente vai limpar. A gente divide as tarefas" (P3). "Ele [o filho] lava a louça ao meio-dia, eu que lavo de noite. Eu vou no mercado com o Cleomar. O Cleomar que faz a janta em quarta-feira" (P2). Um deles relatou procurar manter as atividades domésticas realizadas diariamente e sem a ajuda do filho. "Dou uma organizadinha na casa, limpar o pátio, lavo roupa, limpo casa, vamos no armazém comprar alguma coisa, a gente vai no mercado. Fazer comida, também, eu faço, estou sempre limpando" (P1).

P2 e P3 desempenham as atividades domésticas conjuntamente com os filhos, seja organizando momentos específicos de limpeza, não tão sistematizados, seja dedicando um dia da semana para as atividades de limpeza e manutenção da casa. Ambos encaram essa questão com flexibilidade, encaixando em horários que consideram adequados para a realização. Os dois pais dividem as atividades domésticas com os filhos. Alguns autores afirmam que, nas famílias chefiadas por um dos genitores, há a divisão das tarefas domésticas com os filhos, buscando diminuir o acúmulo para o genitor e, por conseguinte, oportunizam um ambiente colaborativo na família (Souza, 2008). P1, no entanto, demonstrou não dividir as responsabilidades domésticas com seu filho e pareceu encarar essa responsabilidade com maior rigor.

Quanto aos aspectos financeiros, os pais possuem renda e consideram que, com o montante que recebem, conseguem atender às necessidades da família. "Vamos tranquilos. Não vou dizer assim que eu tenho uma vida frouxa, mas também não vou te dizer que é apertado" (P1). "Onde vive uma pessoa, tranquilamente vivem duas" (P2). "Aprendemos a viver com menos grana" (P3). É 
possível perceber que os pais enfrentam certa dificuldade financeira, mas não consideram algo difícil de ser superado, ao contrário de alguns autores que afirmam que as famílias chefiadas por um dos genitores enfrentam dificuldades financeiras (Souza \& Ramires, 2006). Pode-se constatar que, possivelmente, as famílias chefiadas por mulheres encontram maiores e conhecidas dificuldades financeiras pelo motivo de sua histórica dependência econômica do marido, pela maior dificuldade de ingressar no mercado de trabalho e por receberem salários menores que os homens (Brown, 2001; Costa 2002; Garbar \& Theodore, 2000). Isso não pareceu ocorrer nas famílias pesquisadas, que, apesar de afirmarem não serem abastadas economicamente, buscam, por intermédio do planejamento, certo equilíbrio financeiro. É importante considerar que a percepção dos participantes pode estar influenciada pelo contexto cultural tradicional formador do modelo de paternidade, em que o sustento financeiro da família é responsabilidade do pai. Pode ser mais difícil identificar as questões financeiras como dificuldade para quem é tradicionalmente responsável pelo provimento financeiro da família.

Os pais afirmaram que, na medida do possível, fazem um planejamento financeiro, garantindo certa estabilidade financeira familiar, procurando atender primeiramente os filhos. Isso se confirma em: "Aqui, entre aluguel, água e luz, R\$ 500,00, tem mais vestir o Marino" (P1). "Eu preciso fazer muita economia porque o Cleomar, em questão de três anos, quatro anos, ele estará entrando na faculdade" (P2).

Para receber a renda, trabalham em negócios próprios ou, no caso de P1, essa renda é proveniente de uma pensão que recebe da mãe em função do falecimento do pai e também do salário que recebe da empresa onde trabalha. "A minha mãe recebe uma pensão e ela repassa para mim, também, além do meu salário" (P1). "Então eu sempre arrumo alguma forma de fazer o dinheiro entrar" (P2). "Eu sempre fui, eu mesmo, empreendedor. Eu trabalho com Internet" (P3). É possível verificar que dois participantes exercem atividades profissionais liberais, o que facilita $o$ acúmulo de tarefas. Autores discutem sobre a dificuldade que os pais encontram em exercer, simultaneamente, as atividades de sustento do lar, as domésticas e os cuidados com os filhos (Gillies, 2009; Silva \& Piccinini, 2007; Williams, 2008). Diferente é o que denota P1, que mantém vínculo empregatício com uma empresa de transporte de passageiros, porém, exerce, no momento da pesquisa, as atividades que lhes cabem como pai usufruindo de um período de licença do trabalho. Dessa maneira, os pais mantêm financeiramente o lar e, com a flexibilidade dos horários, bem como do local de trabalho, parecem equilibrar as responsabilidades familiares e as profissionais.

Sobre a participação da mãe e da família extensa no cotidiano da família dos participantes, verificou-se que os avós participam com maior proximidade, seguido dos tios que também auxiliam em alguns aspectos, porém de maneira um pouco mais distante. Brown (2001) afirma que o vazio gerado pela ausência da mãe pode ser compensado pelos avós, o que não parece ser exatamente o que ocorre com os casos estudados, ainda que os avós sejam um importante ponto de apoio.

Com relação à participação da mãe na família e na educação e criação dos filhos, um dos pais considera que, mesmo distante, a mãe participa. Já os outros dois pais, embora as mães mantenham contato com os filhos (um (P2) com visitas sistematizadas e outra (P1) com visitas esporádicas), consideram que a participação poderia ser melhor: "Fazem dois anos que ela não vem. Ela liga todo o dia e fica falando com eles. Um dia ela viu os dois brigando aqui: 'Mas o que é isso! Vem cá os dois'. Botou os dois na frente, porque é pela webcam: 'Um pede desculpas para o outro"” (P3). "Não participa" (P1).

Verificou-se que os pais avaliam a participação da mãe de diferentes maneiras. Um deles afirma que a mãe tenta participar do que se refere à educação dos filhos e dos quesitos de afetividade e amorosidade. Porém, as investidas da mãe, embora demonstrem, observando o relato do pai, intenções de proximidade, são limitadas pela distância física, impedindo-a de participar concretamente do cotidiano familiar. O segundo participante, nesse aspecto, avalia que a mãe não participa do cotidiano familiar e nem da educação dos filhos. Afirma que, a partir do momento em que houve a troca da guarda, a mãe distanciou-se do filho, fato que corrobora alguns autores que afirmam que o genitor que não detém a guarda tende a afastar-se do filho (Brown, 2001; Edin, Tach, \& Mincy, 2009; Garbar \& Theodore, 2000; Souza, 2008). Já em relação ao terceiro participante, a mãe acompanha a vida do menino, auxiliando, inclusive, em despesas com medicamentos e material escolar, mantendo, também, as visitas sistemáticas, o que, por conseguinte, favorece a proximidade entre mãe e filho. Tal dinâmica, em certo aspecto, caracteriza uma inversão em relação aos papéis tradicionais já consensuais na sociedade, pois é a mãe, nesse caso, que não detém a guarda do filho, quem atua como suporte financeiro e quem mantém contato com o filho nos dias de visita. Na maior parte das famílias pósdivórcio, em que a mãe está com a guarda do filho, esse papel é exercido pelo pai.

Torna-se evidente a importância que o genitor que não detém a guarda tem para a vida do filho e para a dinâmica familiar. Considerando a fase de adaptação que a família enfrenta quando ocorre o divórcio ou a troca da guarda, a criança é obrigada e enfrentar as mudanças naturais do processo, e, quando ocorre o distanciamento do genitor que não detém a guarda, é outro significativo desafio que se apresenta para o filho. No caso de um dos participantes, 
a presença da mãe foi decisiva, pois, nas dificuldades que o filho encontrou de reproduzir na relação com o pai o que gostava de fazer com a mãe, pôde recorrer a ela. Contraditoriamente à situação de outro destes pais que, com a partida da mãe, temia não conseguir superar a fase de adaptação, observando a dificuldade das crianças.

Observou-se, por meio do estudo, que os demais componentes da família extensa participam basicamente nas atividades do cotidiano familiar. Também auxiliam assumindo as crianças quando os pais saem à noite. Destacam-se os seguintes recortes: "A minha mãe recebe uma pensão e ela repassa para mim. Ele almoçou na minha mãe" (P1). "Então eu quero sair sábado de noite, eles ficam tranquilos com a minha mãe" (P3). Os pais recorrem à família extensa quando ocorre alguma emergência de saúde, por exemplo: "Quando eu me aperto, tem os meus pais. A minha irmã" (P1). Além disso, as famílias também se reúnem para as atividades de lazer: "Chega fim de semana, o meu padrasto pega e liga: ' $\mathrm{P} 1$, não quer vir almoçar aqui?"” (P1).

Quando a mãe deixa vazio o espaço que ocupava, os membros da família de origem ou da extensa podem vir a preencher, conforme Brown (2001), substituindo-a na função materna. Não é o que parece ocorrer nestes casos, já que é o pai que parece tentar compensar este vazio. O que naturalmente pode ocorrer, embora não tenha sido evidenciado no discurso dos pais estudados, mas que se indica, a partir da afirmação de Brown (2001), é a tendência de os familiares interferirem com maior frequência no cotidiano familiar, por vezes, anulando a ação do genitor responsável.

Foi possível verificar que os pais recorrem aos familiares como: mãe, ex-sogra e irmãos para soluções com relação à alimentação, a atividades domésticas, à renda, à compra de material escolar, de medicamento e em situações emergentes, corroborando com os achados de Amazonas, Damaceno, Terto, e Silva, (2003). Na família de um dos pais participantes, a mãe auxilia no preparo do almoço semanal e eventualmente nas demais atividades domésticas. $\mathrm{O}$ segundo recebe auxílio da ex-sogra e de sua mãe na compra de medicamentos, material escolar e vestimentas. O terceiro participante, por sua vez, recebe a participação da mãe na renda financeira e eventualmente nos cuidados com o filho. Conforme Amazonas et al. (2003), as famílias chefiadas por um dos genitores contam com o auxílio da família extensa para amenizar o acúmulo de responsabilidades e de atividades que cabem ao genitor responsável pela família.

\section{Considerações Finais}

Estudar a paternidade num contexto de transformações de paradigmas, como se apresentam na contemporaneidade, evidenciou que não há um modelo único e padronizado de paternidade, assim como não há uma forma de ser pai sem sofrer influência da outra figura parental e dos familiares. Além disso, o pai constitui-se como tal a partir de exemplos que busca em seus próprios pais, bem como em possíveis imagens de outros pais, que considera coerentes com seus princípios. Sendo assim, há pais que exercem a paternidade de maneira não tradicional, o que pressupõe um entendimento do estereótipo de masculinidade diferentemente daquele incorporado pela maioria dos homens até algumas décadas atrás, e há pais que mesclam características dos dois modelos.

É possível verificar que o modelo de pais que os participantes tiveram quando crianças influenciou no exercício da paternidade. Os aspectos positivos da paternidade exercidos pelos seus pais foram seguidos e os negativos abandonados. Nesses casos, em que o pai está com a guarda do filho, os participantes afirmam a importância de estarem próximos dos filhos, ao mesmo tempo em que garantem o sustento do lar. Apontam, também, para a importância que o estilo de paternidade que circula pelos diversos microssistemas intrafamiliares, a saber, educação, higiene, saúde, lazer, finanças, tem para a criação de seus filhos e para a constituição de uma família pós-divórcio chefiada pelo pai.

Independentemente dos modelos paternos serem assimilados negativa ou positivamente, exercem a paternidade voltada a priorizar as necessidades dos filhos, desvinculando-se do modelo tradicional de paternidade. É possível pensar que esse modelo de pai é que tende a buscar a guarda dos filhos, pois percebem o quanto podem vencer o desafio de criar os filhos próximos deles, do lar, da família e não se eximindo da responsabilidade de provedor.

Evidenciou-se que o exercício da paternidade se intensificou após a separação e posse da guarda paterna dos filhos. É possível que, durante a conjugalidade, os cuidados e a educação dos filhos, as tarefas domésticas, a manutenção financeira da família, os momentos de lazer e de dificuldades sejam divididos entre o casal. Com a separação e com a guarda do filho sob responsabilidade do pai, este passa a exercer a paternidade com menor ou nenhuma participação da mãe, o que pode aproximar pai e filho e possibilitar a vivência de momentos antes não experienciados. Além disso, o pai que se torna unicamente responsável pela família, precisa se reorganizar com as atividades domésticas, bem como financeiramente. Por isso, é possível que a família de origem sirva de apoio para algumas dificuldades que o pai e seus filhos possam encontrar. Destaca-se, no entanto, que esse mesmo apoio é menor ao se tratar da mãe, ex-esposa do pai, conforme pode ser observado nos resultados deste estudo.

Nesse contexto, desejar ser pai e, ainda mais, desejar 
cumprir as responsabilidades de pai é imprescindível. Pensar a paternidade é muito mais do que pensar apenas a criação biológica de um filho: é pensar nas mudanças comportamentais, econômicas e sociais decorrentes da assunção desse papel, as quais ocorrem principalmente com o homem, mas também impactam os demais componentes familiares. O tipo de pai que será passa, em certa medida, pelo crivo da própria consciência que elege imagens e modelos de paternidade que estão incorporadas em si mesmo. Além disso, as mudanças em relação à paternidade continuarão ocorrendo até a criação do último filho, ou mesmo durante a totalidade da vida, já que, mesmo separado, nunca deixará de ser pai (Colman \& Colman, 1988). A cada momento de relação com os filhos, pode modificar sua maneira de exercer a paternidade, considerando que, a cada movimento, pode reconsiderar diretrizes, rever decisões e, assim, recriar e remodelar a paternidade que não está fechada e imutável, pelo contrário, está em constante formação e constituição.

Nesse sentido, ficam abertas sugestões para futuros estudos que considerem a paternidade em famílias constituídas pelo pai e pelos filhos, com o objetivo de ampliar o olhar sobre esse contexto familiar. Este estudo apresenta suas limitações, pois, considerando a quantidade de participantes e por ser um estudo em profundidade, não é passível de generalizações. O fator desejabilidade social apresenta-se como outro possível limitador, já que os pais podem ter omitido informações negativas de seu exercício da paternidade, revelando ao pesquisador ou ao meio externo aquilo que consideram apropriado, uma vez que revelam a forte exigência que sofrem no desempenho efetivo do seu papel como principal cuidador dos filhos. Porém, com a ampliação de estudos nesta área, com novos olhares, é possível enriquecer a discussão sobre a paternidade em famílias nas quais os pais ficam com a guarda dos filhos após o divórcio, considerando que essa é uma realidade que tende a se tornar mais comum em nossos contextos.

\section{Referências}

Amazonas, M. C. L. de A., Damaceno, P. R., Terto, L. de M. de S., \& Silva, R. R. da. (2003). Arranjos familiares de crianças das camadas populares. Psicologia em Estudo, 8, 11-20.

Badinter, E. (1993). XY: Sobre a identidade masculina (M. I. D. Estrada, Trad.). Rio de Janeiro: Nova Fronteira.

Bandeira, T. T. A., \& Seidl-de-Moura, M. L. (2012). Crenças de pais e mães sobre o investimento parental. Paidéia, $22(53), 355-363$.

Bardin, L. (2009). Análise de conteúdo (L. A. Reto, \& A. Pinheiro, Trads., $4^{\mathrm{a}}$ ed.). Lisboa: Edições 70.
Brown, F. H. (2001). A família pós-divórcio. In B. Carter, \& M. McGoldrick (Orgs.), As mudanças no ciclo de vida familiar: Uma estrutura para a terapia familiar (M. A. V. Veronese, Trad., $2^{a}$ ed., pp. 291-320). Porto Alegre: Artes Médicas.

Creswell, J. W. (2007). Projeto de pesquisa: métodos qualitativo, quantitativo e misto (L. de O. da Rocha, Trad., 2a ed.). Porto Alegre: Bookman.

Colman, A., \& Colman, L. (1988). O pai: Mitologia e reinterpretação dos arquétipos (A. U. Sobral, Trad.). São Paulo: Cultrix.

Costa, D. D. da. (2002). Famílias monoparentais: Reconhecimento jurídico. Rio de Janeiro: Aide.

Dantas, C. R. T. (2003). O exercício da paternidade após a separação: Um estudo sobre a construção $e$ a manutenção do vínculo afetivo entre pais e filhos na família contemporânea. Dissertação de Mestrado, Pontifícia Universidade Católica do Rio de Janeiro, RJ.

Edin, K., Tach, L., \& Mincy, R. (2009). Claiming fatherhood: Race and the dynamics of paternal involvement among unmarried men. American Academy of Political and Social Science, 621, 149-177.

Eggebeen, D. J. (2002). The changing course of fatherhood: men's experiences with children in demographic perspective. Journal of Family Issues, 23(4), 486-506.

Eggebeen, D. J., Snyder, A. R., \& Manning, W. D. (1996). Children in single-father families in demographic perspective. Journal of Family Issues, 17(4), 441-465.

Freitas, W. de M. F., Coelho, E. de A. C., \& Silva, A. T. M. C. da. (2007). Sentir-se pai: A vivência masculina sob o olhar de gênero. Cadernos Saúde Pública, 23(1), 137-145.

Gabriel, M. R., \& Dias, A. C. G. (2011). Percepção sobre a paternidade: Descrevendo a si mesmo e o próprio pai como pai. Estudos de Psicologia, 16(3), 253-261.

Garbar, G., \& Theodore, F. (2000). Família mosaico (L. Lopreto, Trad.). São Paulo: Augustus.

Garasky, S., \& Meyer, D.R. (1996). Reconsidering the Increase in Father-Only Families. Demography, 33(3), 385-393.

Gillies, V. (2009). Understandings and experiences of involved fathering in the United Kingdom: Exploring classed dimensions. The Annals of the American Academy of Political and Social Science, 624, 49-60.

Grzybowski, L. S. (2007). Parentalidade em tempos de mudança: Desvelando o envolvimento parental após 
o fim do casamento. Tese de Doutorado, Pontifícia Universidade Católica do Rio Grande do Sul, RS.

Hennigen, I. (2010). Especialistas advertem: O pai é importante para o desenvolvimento infantil. Fractal: Revista de Psicologia, 22(1), 169-184.

Hook, J. L., \& Chalasani, S. (2008). Gendered Expectations? Reconsidering Single Fathers' Child-Care Time. Journal of Marriage and Family, 70, 978-990.

Instituto Brasileiro de Geografia e Estatística [IBGE], Estatísticas do Registro Civil. (1998). Recuperado em Outubro 10, 2010 de http://www.sidra.ibge.gov.br

Instituto Brasileiro de Geografia e Estatística [IBGE], Estatísticas do Registro Civil. (2008). Recuperado em Outubro 10, 2010 de http://www.sidra.ibge.gov.br

Kehl, M. R. (1996). A mínima diferença: Masculino e feminino na cultura. Rio de Janeiro: Imago.

Jiménez, A. C. (2003). La relación padres-hijos escolares em familias monoparentales de um contexto mexicano. Revista Cubana de Psicologia, 20(1), 91-94.

Leininger, L. J., \& Ziol-Guest, K. M. (2008). Reexamining the Effects of Family Structure on Children's Access to Care: The Single-Father Family. Health Services Research, 43(1), 117-133.

Magalhães, A. S. (2007). Novos arranjos familiares: Qual é o papel do pai na família contemporânea? IHU on-line, 230, 10-11. Recuperado em Março 19, 2010 de http:// www.ihuonline.unisinos.br/index.php?option=com_co ntent\&view $=$ article \&id $=1184 \&$ secao $=230$

Moreira, L. E., \& Toneli, M. J. F. (2013). Paternidade responsável: Problematizando a responsabilidade paterna. Psicologia \& Sociedade, 25(2), 388-398.

Piccinini, C. A., Silva, M. da R., Gonçalves, T. R., Lopes, R. de C. S., \& Tudge, J. (2012). Envolvimento paterno aos três meses de vida do bebê. Psicologia: Teoria e Pesquisa, 28(3), 303-314.

Silva, M. da R. (2003). Sentimentos sobre a paternidade e envolvimento de pais que residem e pais que não residem com seus filhos. Dissertação de mestrado, Universidade Federal do Rio Grande do Sul, RS.

Silva, M. da R., \& Piccinini, C. A. (2007). Sentimento sobre a paternidade e o envolvimento paterno: um estudo qualitativo. Estudos de Psicologia, 24(4), 561-573.

Souza, A. P. de. (2008). Estudo comparativo das famílias monoparentais masculinas $x$ monoparentais femininas: A influência do genitor no desenvolvimento familiar. Dissertação de mestrado, Universidade Estadual de
São Paulo, SP.

Souza, C. L. C. de., \& Benetti, S. P. da C. (2009). Paternidade contemporânea: levantamento da produção acadêmica no período de 2000 a 2007. Paideia, 19(42), 97-106.

Souza, R. M. de., \& Ramires, V. R. R. (2006). Amor, casamento, família, divórcio... e depois, segundo as crianças. São Paulo: Summus.

Staudt, A. C. P. (2007). Novos tempos, novos pais? O ser pai na contemporaneidade. Dissertação de mestrado, Pontifícia Universidade Católica do Rio Grande do Sul, RS.

Staudt, A. C. P., \& Wagner, A. (2008). Paternidade em tempos de mudança. Psicologia: Teoria e Prática, 10(I), 174-185.

Yablonsky, L. (1990). Pais e filhos (A. Cancian, Trad., 10a ed.). São Paulo: Melhoramentos.

Williams, S. (2008). What is Fatherhood? Searching for the Reflexive Father. Sociology, 42(3), 487-502.

Ziol-Guest, K. M. (2009). A Single Father's Shopping Bag: Purchasing Decisions in Single-Father Families. Jornal of Family Issues, 30, 605-622.

\section{Endereço para correspondência:}

Rogério Isotton

Endereço: Rua Independência, $n^{\circ}$ 181/904, Centro.

São Leopoldo/RS. - CEP: 93010-001

E-mail: risotton@hotmail.com

\section{Endereço para correspondência:}

Denise Falcke

Endereço: Av. Unisinos, no 950, São João Batista.

São Leopoldo/RS. - CEP: 93022-000

E-mail: dfalcke@unisinos.br 